INRA Prod. Anim., 2006, 19 (2), 69-78

\title{
Le contrôle de l'acidose ruminale latente
}

\author{
D. Sauvant, S. Giger-Reverdin, F. Meschy
} INRA, INA Paris-Grignon, UMR Physiologie de la Nutrition et Alimentation, 16 rue Claude Bernard, F-75231 Paris cedex 05 Courriel :sauvant@inapg.inra.fr

Comme l'indique l'introduction générale (Sauvant et al 2006), on distingue deux formes principales de l'acidose ruminale (Owens et al 1998) : aiguë et latente. L'acidose ruminale aiguë est une situation accidentelle qui ne sera pas abordée dans ce texte. L'acidose latente (ou sub-clinique) est un phénomène plus complexe intervenant dans des situations où le $\mathrm{pH}$ ruminal se situe pendant de longues périodes au cours de la journée entre des valeurs comprises entre 5,5 et 6,2 environ. C'est une situation courante pour des animaux à haut niveau de production qui reçoivent des rations riches en concentré dans le but de satisfaire leurs besoins énergétiques. Des valeurs basses de $\mathrm{pH}$ ruminal réduisent la valeur énergétique du régime, en particulier de sa fraction fourrage. En outre, lors d'acidose latente, le profil des Acides Gras Volatils $(\mathrm{AGV}) \mathrm{du}$ jus de rumen est modifié, avec des valeurs faibles du rapport acétate/propionate, entraînant une modification des métabolismes avec, dans le cas des ruminants laitiers, une chute du taux butyreux du lait associée à un engraissement excessif. Plusieurs troubles sont associés à l'acidose latente - pour constituer en fait un syndrome. Il s'agit en particulier des déplacements de la caillette, d'abcès du foie, d'une sensibilité podale excessive et, de ce fait, des problèmes de boiterie.

L'objectif de cet article est de fournir une revue quantitative des principaux facteurs de variation et moyens de contrôle de l'acidose ruminale. En particulier, nous nous attacherons à dégager les principales caractéristiques des aliments et des rations pouvant être utilisées pour prévenir le risque d'acidose. Les caractéristiques considérées ont été essentiellement mesurées chez des bovins, cependant les phénomènes peuvent être transcrits de façon comparable chez les ovins et les caprins.

\section{1 / Les critères d'évaluation de l'acidose ruminale}

La valeur moyenne du $\mathrm{pH}$ ruminal constitue le principal indicateur pour évaluer le statut acidosique ruminal. Cette valeur du $\mathrm{pH}$ est généralement mesurée sur des périodes de 6 à 12 heures. Dans notre base de données, développée depuis 7 ans (Sauvant et Mertens non publié), sur 1002 traitements, les paramètres statistiques du $\mathrm{pH}$ moyen du rumen ont été 6,23 (moyenne), 0,33 (écart-type = e.t.), 5,30 (minimum) et 7,24 (maximum). Comme le $\mathrm{pH}$ varie largement après le repas, plusieurs paramètres caractérisant la cinétique du $\mathrm{pH}$ ont été proposés comme nouveaux critères d'évaluation : durée du $\mathrm{pH}$ sous un seuil donné $(6,0$ ou 6,2$)$, aire sous cette valeur seuil, variation du $\mathrm{pH}$ dans la journée... Dragomir et al (2005) ont conduit récemment une revue quantitative de la littérature comprenant 219 cinétiques de $\mathrm{pH}$ publiées dans 48 articles. Ce travail suggère que la plupart de ces autres paramètres sont étroitement liés avec la valeur moyenne du $\mathrm{pH}$ et qu'aucun d'entre eux n'apparaît comme supérieur aux autres pour évaluer le statut acidosique d'un ruminant.

Comme le $\mathrm{pH}$ résulte d'abord de la concentration en AGV dans le rumen, ce paramètre peut également être utilisé pour évaluer l'état d'acidose ruminal. En fait, $\mathrm{pH}$ et $[\mathrm{AGV}](\mathrm{mmol} / \mathrm{L})$ sont significativement liés :

$$
\begin{gathered}
\mathbf{p H}=\mathbf{6 , 9 6}-\mathbf{0 , 0 0 7}[\mathbf{A G V}] \\
\left(n=807, \mathrm{R}^{2}=0,28, \text { etr }=0,26\right)
\end{gathered}
$$

Cette régression globale, extraite de la base de données susmentionnée, indique que, pour une valeur donnée de concentration en $\mathrm{AGV}$, l'étendue des valeurs de $\mathrm{pH}$ correspondante est relativement large (d'environ 1 point). La variation résiduelle de l'équation ci-dessus peut être considérée comme un index de la capacité tampon du contenu ruminal. Les valeurs positives s'observent pour des régimes présentant de fortes teneurs en parois végétales, estimée par le résidu NDF, ou des valeurs élevées d'indices de mastication (mn de mastication par $\mathrm{kg}$ de MSI). Ces valeurs indiquent un contenu ruminal bien tamponné. Au contraire, des valeurs négatives des résidus, observées avec des régimes riches en concentré ou en amidon, traduisent l'existence d'un jus de rumen insuffisamment tamponné.

Ceci montre que le couple $(\mathrm{pH}$, [AGV]) peut être utilisé en association avec l'équation ci-dessus pour évaluer la capacité de tampon du rumen. Par exemple, avec la base de données sur l'apport de substances tampons alimentaires, citée ci-dessous (cf § 2.6), la valeur moyenne de l'écart à l'équation ci-dessus était de - 0,04 pour les régimes témoins et de $+0,10$ pour les régimes supplémentés en tampons (70 traitements, 35 expériences). Cette différence de 0,14 point $\mathrm{pH}$ est très significative alors que la teneur en [AGV] du jus n'est pas modifiée par l'apport des tampons.

Si seul le pH est connu, il convient de se rappeler que la capacité tampon du jus de rumen s'accroît lorsque le $\mathrm{pH}$ décroît en dessous de la neutralité (Giger-Reverdin et al 2003, Martin et al 2006).

D'autre part, comme le profil des $\mathrm{AGV}$ du rumen est étroitement lié à la valeur de $\mathrm{pH}$, il peut être utilisé comme un indicateur de la nature des fermentations ruminales. En particulier, le rapport acétate/propionate $(\mathrm{A} / \mathrm{P})$ qui est un index du statut énergétique des microbes (Sauvant et Van Milgen 1995), est lié positivement et assez précisément au $\mathrm{pH}$ du rumen. On considère généralement que les fermentations ruminales sont instables lorsque $\mathrm{A} / \mathrm{P}<3,0$. Cette 
valeur correspond approximativement à $\mathrm{pH}=6,0$. Il convient également de se souvenir que les variations du rapport entre $\mathrm{A} / \mathrm{P}$ ont une influence sur le statut métabolique énergétique de l'animal et la partition de certains flux de nutriments. Ainsi, des conditions instables se traduisent par des orientations métaboliques favorables à l'engraissement au détriment de la production de matière grasse laitière.

\section{2 / Contrôle de l'acidogéni- cité des aliments et des régi- mes par des attributs non fibreux}

\section{1 / Le pouvoir tampon des aliments}

Chaque aliment possède un Pouvoir Tampon (PT) spécifique qui influence la cinétique du $\mathrm{pH}$ lorsque de l'acide (acide acétique, par exemple) est ajouté au milieu. Plus précisément, PT est égal à l'inverse de la valeur de la fonction dérivée qui caractérise le changement de $\mathrm{pH}$ après addition d'acide acétique. Ce pouvoir se mesure en partant du $\mathrm{pH}$ initial $\left(\mathrm{pH}_{\mathrm{j}}\right)$ de l'aliment, qui peut être différent d'un aliment à l'autre. Pour évaluer les causes et l'étendue des variations du PT des aliments, GigerReverdin et al (2002) ont conduit une étude spécifique sur 24 aliments courants, fourrage, concentrés ou coproduits. La plupart des aliments considérés présentent un PT compris entre 0,20 (sorgho) et 2,20 (foin de luzerne), cependant quelques-uns ont une valeur très élevée, c'est par exemple le cas du glutenmeal $(4,51)$, des drèches de brasserie $(8,60)$ et du corn gluten feed $(19,64)$. Les principaux facteurs de variations du PT ont été les teneurs en Matières Minérales (MM, effet favorable) et en Matières Azotées Totales (MAT, effet favorable). Il convient de noter que le $\mathrm{pH}$ initial des aliments a varié de 3,89 (ensilage de maïs) à 6,76 (tourteaux de soja). $\mathrm{Ce} \mathrm{pH}_{\mathrm{i}}$ présente aussi une influence sur le PT des aliments. Une régression multiple peut expliquer la majeure partie des variations du pouvoir tampon des aliments :

$\mathrm{PT}=4,96-0,810 \mathrm{pH}_{\mathrm{i}}+0,0114 \mathrm{MM}$

$(\mathrm{g} / \mathrm{kg}$ MS) + 0,00137 MAT (g/kg MS) $\left(n=24\right.$, etr $\left.=0,24, \mathrm{R}^{2}=84,6 \%\right)$

\section{2 / L'acidogénicité in vitro des aliments}

Plusieurs études ont montré qu'il y avait de larges variations dans l'aptitu- de des aliments à faire chuter le $\mathrm{pH}$ du jus de rumen in vitro. En conséquence, Giger-Reverdin et Sauvant (2001) ont étudié la cohérence entre les échelles d'acidogénicité publiées dans quatre articles de la littérature. Il a été ainsi possible de classer 14 ingrédients courants quant à leurs valeurs de $\mathrm{pH}$ induites in vitro après quelques heures d'incubation.

Pour ces 14 ingrédients, le classement obtenu a été le suivant, en allant $\mathrm{du}$ plus acidogène à celui qui l'est le moins. Deux valeurs sont indiquées, le $\mathrm{pH}$ moyen obtenu et son écart-type. Le classement est le suivant : manioc $(5,70,0,10)$, orge $(5,77,0,06)$, pulpe d'agrumes $(5,82,0,07)$, blé $(5,84$, $0,06)$, glutenfeed $(5,86,0,07)$, avoine $(5,87,0,08)$, son de blé $(5,87,0,08)$, pulpe de betteraves $(5,89,0,06)$, tourteaux de colza $(5,95,0,08)$, tourteaux de coprah $(5,98,0,08)$, coques de soja $(6,00,0,07)$, tourteaux de soja $(6,01$, $0,07)$, maïs $(6,04,0,06)$ et sorgho $(6,10$, $0,06)$. Etant donné qu'il n'y a pas d'interaction aliments/publications, cette hiérarchie présente une portée générale.

Signalons enfin que la production de gaz in vitro fournit des hiérarchies d'aliments comparables à celles obtenues pour le pH (Giger-Reverdin et al 2000).

\section{3 / La dégradation à court terme de la matière sèche in sacco}

La disparition de la matière sèche in sacco (DMS, \% MS) à court terme, après 4 heures d'incubation, est étroitement liée aux valeurs de $\mathrm{pH}$ in vitro évoquées précédemment pour les 14 aliments (figure 1) :

$$
\begin{aligned}
& \text { pH }=6,18-0,0049 \text { DMS }_{4 h} \\
& (n=14, \text { etr }=0,06)
\end{aligned}
$$

Comme la $\mathrm{DMS}_{4 \mathrm{~h}}$ (désignée par MSrap dans le texte de Peyraud et Apper-Bossard 2006) a été fréquemment mesurée, Chapoutot et al (non publié), ont effectué une synthèse de ces valeurs à travers les données de la littérature. Les principaux résultats obtenus par cette analyse ont été cités dans les Tables INRA-AFZ (Sauvant $e t$ al 2002). Les valeurs de $\mathrm{DMS}_{4 \mathrm{~h}}$ se situent entre 5 et $75 \% \mathrm{MS}$, on considère que l'acidogénéicité d'un aliment devient importante lorsque $\mathrm{DMS}_{4 \mathrm{~h}}>$ $50 \%$. Les valeurs de $\mathrm{DMS}_{4 \mathrm{~h}}$ peuvent être considérées comme additives et peuvent donc être prises en compte dans la formulation des aliments.

\section{4 / La teneur en amidon dégra- dable dans le rumen}

Les mesures d'acidogénicité in vitro évoquées plus haut ont montré que les matières premières amylacées étaient plus ou moins acidogènes en fonction de la vitesse de dégradation de leurs fractions d'amidon dans le rumen. Ainsi, les amidons «rapides» (manioc, orge, blé...) sont plus acidogènes que les amidons «lents» (maïs et sorgho). Pour confirmer ces phénomènes avec des rations, Offner et al (2003) ont rassemblé une base de données incluant 101 expériences et 253 traitements.

Figure 1. Relation entre le pouvoir acidogène des aliments et la dégradation de leur matière sèche in sacco.

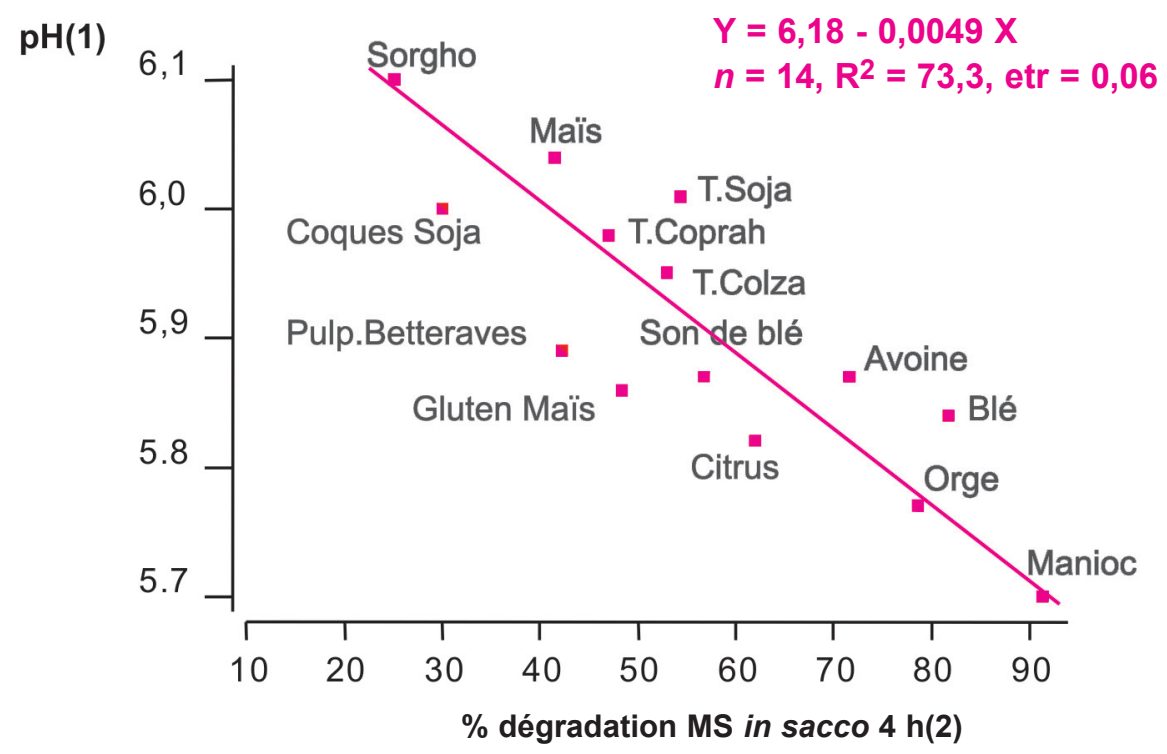

Synthèse bibliographique de S. Giger Reverdin et D. Sauvant.

Synthèse des données de P. Chapoutot. 
Pour être incluse dans la base, une expérience devait présenter des résultats de teneurs en amidon digestible des aliments dans le rumen (AMDRu\%MSI) ainsi que le $\mathrm{pH}$ du jus de rumen. Le calcul de AMDru nécessite de connaître la teneur en amidon et sa digestion entre l'ingéré et le duodénum. L'étendue de la digestion de l'amidon dans le rumen a été importante $(0$ à $68 \%)$ et il apparaît une relation intra-expérience étroite entre le $\mathrm{pH}$ moyen du rumen et la teneur en amidon digestible (figure 2). Cette relation est commune aux bovins viande et lait :

$$
\begin{gathered}
\mathbf{p H}=\mathbf{6 , 4}-\mathbf{0 . 0 1} \mathbf{A M D R u} \% \\
\left(n=253, \text { nexp }=101, \mathrm{R}^{2}=0,93, \text { etr }=0,12\right)
\end{gathered}
$$

Cette équation de régression suggère que le $\mathrm{pH}$ devient inférieur à 6 lorsque la teneur en amidon digéré dans le rumen $(\mathrm{AMDRu})$ est supérieure à $40 \%$ MS.

\section{5 / L'équilibre électrolytique des aliments et des régimes}

L'absorption digestive des cations tels que $\mathrm{Na}^{+}$et $\mathrm{K}^{+}$induit en échange des sorties d'ions $\mathrm{H}^{+}$du pool sanguin, en conséquence, les cations alimentaires peuvent être considérés comme anti-acidogènes au niveau métabolique. $\mathrm{Au}$ contraire, l'absorption des anions tels que $\mathrm{Cl}^{-}$et $\mathrm{S}^{--}$sont échangés avec des ions $\mathrm{HCO}_{3}{ }^{-}$du pool sanguin et de liquides extra-cellulaires, ils peuvent donc être considérés comme acidogènes. Pour intégrer ces deux aspects, il a été suggéré de calculer le «bilan électrolytique» (BE, (Sauveur et Mongin 1978)) :

\section{$\mathrm{BE}(\mathrm{mEq} / \mathrm{kg} \mathrm{MS})=\left[\mathrm{Na}^{+}+\mathrm{K}^{+}\right]-\left[\mathrm{Cl}^{-}\right]$}

ou bien la différence cations-anions (DCA) ou Bilan Anion-Cation (BACA, Dishington 1975) des aliments :

\section{BACA $(\mathrm{mEq} / \mathrm{kg} \mathrm{MS})=$ $\left[\mathrm{K}^{+}+\mathrm{Na}^{+}\right]-\left[\mathrm{Cl}^{-}+\mathrm{S}^{--}\right]$}

Ces deux paramètres sont en fait étroitement liés $(\mathrm{BE}=\mathrm{BACA}+150$, $n=113, \mathrm{R}^{2}=0,80$, etr $=80$ pour les aliments concentrés et $\mathrm{BE}=1,13 \mathrm{BACA}+$ $41, n=1320, \mathrm{R}^{2}=0,97$, etr $=34$ pour les fourrages). De faibles valeurs de BE ou de BACA $(<120-150 \mathrm{mEq} / \mathrm{KG}$ MSI) suggèrent une acidogénicité métabolique élevée. Les valeurs de $\mathrm{BE}$ et de BACA ont été indiquées pour les aliments concentrés et coproduits dans les Tables INRA-AFZ. Des valeurs ont également été publiées pour les fourrages (Meschy et Peyraud 2004), certai-

Figure 2. Influence de la teneur en amidon digestible dans le rumen sur le ph ruminal (Offner et al 2003).

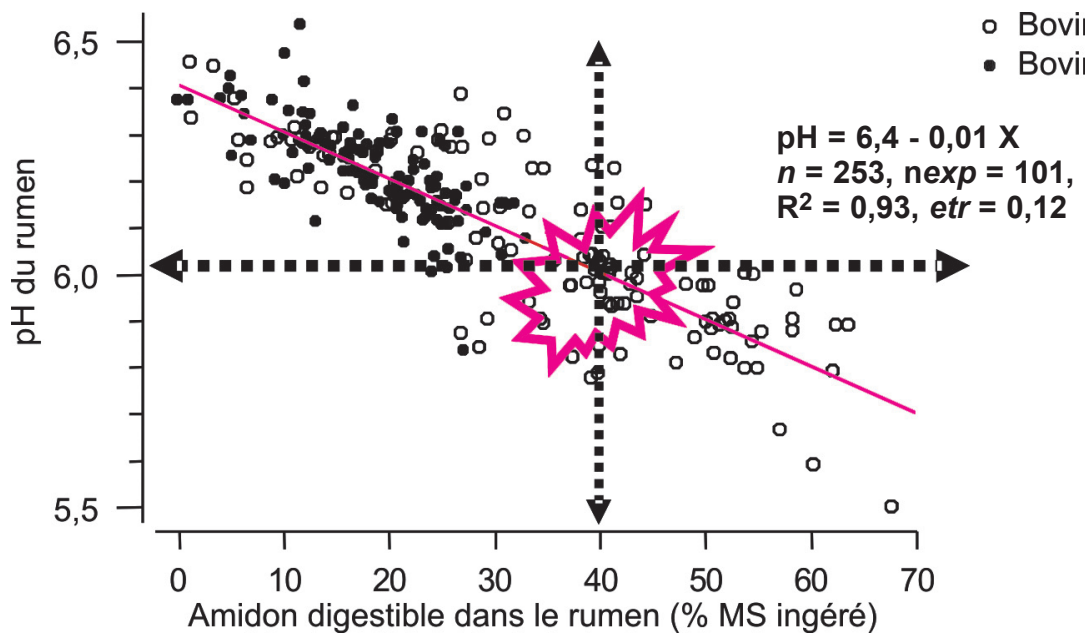

nes sont présentées dans un des deux autres articles de ce dossier d'INRA Productions Animales (Peyraud et Apper-Bossard 2006).

Des travaux récents conduits à l'INRA, UMR PL de Rennes, ont confirmé que les critères de BE ou de BACA étaient fiables pour évaluer les effets défavorables d'une acidogénécité élevée sur 1'homéostase des ions $\mathrm{H}+$ ainsi que sur l'ingestion et la production laitière (Apper-Bossard et al 2004, Peyraud et Apper-Bossard 2006).

\section{6 / L'apport de substances tampons}

Une pratique courante pour prévenir l'acidose latente est de supplémenter les régimes avec une substance tampon, le bicarbonate de sodium le plus souvent. Le niveau de supplémentation recommandé est de l'ordre de $1 \% \mathrm{MS}$ du régime. Dans une revue récente, conduite sur une base de 86 expériences et 118 traitements, Meschy et al (2004) ont montré qu'un apport de tampon chez la vache laitière permettait d'accroître significativement la matière sèche ingérée $(+0,63 \pm 1.05 \mathrm{~kg} / \mathrm{j}$, $n=91)$, le $\mathrm{pH}$ du rumen $(+0,12 \pm 0,19$, $n=49)$, le rapport acétate/propionate du jus de rumen $(+0.19 \pm 0.39, n=60)$, la digestibilité de la fraction lignocellulose ou ADF $(+3,62 \pm 4.8 \%, n=23)$ et le taux butyreux du lait $(+1,9 \pm$ $2,6 \mathrm{~g} / \mathrm{kg}, n=90$ ).

En outre, des relations significatives et logiques ont associé les réponses du $\mathrm{pH}$ du rumen avec celles du rapport acétate/propionate et du TB du lait. Il convient de souligner que des interactions significatives sont observées lors d'apport de bicarbonates en fonction des niveaux initiaux des valeurs de $\mathrm{pH}$,
A/P et du TB. Plus précisément, lorsque les régimes aboutissent à des valeurs normales du $\mathrm{pH}$ (environ 6,7), du rapport $\mathrm{A} / \mathrm{P}$ (environ 3) et du TB du lait (environ $40 \mathrm{~g} / \mathrm{kg}$ ), il n'y a pas d'effet de l'apport de tampons alimentaires. Par contre, l'effet de ces tampons s'accroît lorsque les valeurs de ces trois paramètres diminuent. En conséquence, l'opportunité pratique de l'apport de tampons s'accroît avec le niveau d'acidose ruminale. L'intégration de l'apport des tampons dans le régime peut se faire en formulant en termes de bicarbonate \% MSI, ou en terme de BE ou de BACA. La valeur BACA du bicarbonate est très élevée $(12000 \mathrm{mEq} / \mathrm{kg})$ comparée aux valeurs généralement observées pour les aliments $(-200$ à $+500 \mathrm{mEq} / \mathrm{kg})$. Sur les aspects métaboliques, ce travail a également montré que l'apport de tampons alimentaires accroissait significativement la teneur en bicarbonate du plasma $(+0,61 \pm 1,0 \mathrm{mmole} / \mathrm{L}$, $n=19)$ et le $\mathrm{pH}$ urinaire $(+0,28 \pm 0,16$, $n=17)$.

\section{7 / La fourniture de probio- tiques}

Les effets de l'influence des probiotiques sur la gestion de l'acidose ruminale varient assez largement selon les publications. Pour en dégager des tendances et des effets, nous avons effectué une revue de la littérature sur ce sujet (Sauvant et al 2004). In vitro, la supplémentation en levure accroît le $\mathrm{pH}(6,35$ vs 6,32, $n=94$, nexp $=37$, etr $=0,05, \mathrm{p}=0,028)$, cependant il n'y a pas eu d'effet du traitement sur la concentration en $\mathrm{AGV}$, suggérant ainsi une influence sur le pouvoir tampon du jus de rumen. In vivo, il n'y a pas eu d'augmentation significative du $\mathrm{pH}$ avec la levure $(6,34$ vs $6,32, n=168$, nexp $=70$, etr $=0,015, \mathrm{p}=0,288)$. Il en 
a été de même pour les concentrations en $\operatorname{AGV}(99,1$ vs 97,8 1, $n=156$, nexp $=64, \mathrm{rsd}=75,8 \mathrm{mM}, \mathrm{p}=0,386)$, pour le rapport $\mathrm{A} / \mathrm{P}(3,24$ vs $3,17, n=163$, nexp $=69$, rsd $=0,078, \mathrm{p}=0,110$ ) et pour la concentration en acide lactique $(1,38$ vs $1,45, n=39$, nexp $=15$, etr $=$ $0,417 \mathrm{p}=0,729)$. Ces résultats doivent cependant être considérés avec prudence car la méta-analyse effectuée avait regroupé les essais «toutes rations confondues»; en outre, tous les types de levures avaient été considérés comme analogues.

Sur des essais in vivo, il a été confirmé que les levures pouvaient accroître la capacité tampon du rumen (GigerReverdin et al 2004, Brossard 2004, Brossard et al 2006).

Il avait été également montré in vitro que la levure pouvait décroître la concentration en acide lactique dans le rumen par simulation de l'activité des bactéries utilisatrices de lactate (Selenomonas ruminantium, Megasphaera elsdenii) via l'apport de facteurs de croissance (Nisbet et Martin 1991, Chaucheyras 1995, Rossi et al 1995).

Un nouveau mode d'action des levures a été proposé récemment par Brossard 2004 (chez des animaux en situation d'acidose latente de type butyrique sans accumulation de lactate et sans développement des bactéries impliquées dans le métabolisme du lactate (BML) : les levures stimuleraient la population des protozoaires. Ceci renforcerait le rôle stabilisateur des protozoaires durant l'acidose ruminale latente en limitant l'accès des BML à l'amidon.

Chez les bovins laitiers, il semble que la levure soit plus efficace pour restaurer le TB du lait quand ce dernier présente de faibles valeurs révélant peutêtre un état de subacidose ruminale (Sauvant et al 2004).

\section{3 / Contrôle de l'acidose ruminale à partir des carac- téristiques de fibrosité}

Etant donné que de nombreuses études sont focalisées sur l'influence des variations des fibres chimiques (paroi végétale) ou physiques (taille des particules) sur le $\mathrm{pH}$ du rumen ou d'autres caractéristiques liées, il a été décidé d'effectuer des méta-analyses sur ces différentes études (Sauvant et Mertens
2001). Dans ce but, deux bases de données spécifiques ont été construites :

- la première base a regroupé des expérimentations dans lesquelles les teneurs en NDF, ou \% concentré, constituaient le facteur expérimental. Après exclusion des expérimentations pour lesquelles NDF > $50 \% \mathrm{MS}$, la base comprenait 35 publications, 46 expériences et 120 traitements. Les statistiques de base ont été, pour le NDF, $32,2 \pm 6,2 \% \mathrm{MS}$ et, pour le $\mathrm{pH}, 6,16$ $\pm 0,30$.

- la seconde base sur la fibre physique a regroupé des expérimentations dans lesquelles la taille des particules était le facteur étudié. Elle comprenait 12 publications, 19 expérimentations et 51 traitements. Les statistiques de base étaient, pour la taille des particules, (TPa) 2,59 $\pm 1,48 \mathrm{~mm}$ et, pour le $\mathrm{pH}$, $6,25 \pm 0,32$.

Les valeurs de $\mathrm{pH}$ étaient du même ordre de grandeur entre les deux bases. Celles-ci ont été ajustées par des modèles d'analyse de variance-covariance (Sauvant et al 2005). Ces méthodes statistiques ont permis d'investiguer les relations entre et à l'intérieur des différentes expérimentations. En outre, des interactions entre expérimentations et covariables ont été testées.

\section{1 / Contrôle par les fibres chimiques}

Il n'apparaît pas d'influence des variations en teneurs en NDF du régime lorsque celles-ci sont supérieures à $45 \%$ MS. En dessous de cette valeur, il y a une influence significative mais également une interaction entre expériences $(E)$ et teneurs en NDF (figure 3) :

$$
\begin{gathered}
\mathbf{p H}=\mathbf{5 , 2 5}+\mathbf{0 , 0 2 8} \mathbf{N D F}+\mathbf{0 , 0 2 5} \mathbf{E} * \mathbf{N D F} \\
\left(n=120, \mathrm{R}^{2}=0,98, \text { etr }=0,09\right)
\end{gathered}
$$

Ainsi la pente ajustée de la réponse $\mathrm{du} \mathrm{pH}$ est plus sensible aux variations de NDF lorsque la valeur moyenne du $\mathrm{pH}$ ruminal est déjà faible :

$$
\begin{aligned}
& \mathrm{dpH} / \mathrm{dNDF}=0,018 \text { quand } \mathrm{pH}=6,5 \\
& \mathrm{dpH} / \mathrm{dNDF}=0,037 \text { quand } \mathrm{pH}=5,8
\end{aligned}
$$

En conclusion de cette partie, la teneur minimale en fibres chimiques qui doit être respectée pour maintenir un $\mathrm{pH}$ correct tout en tenant compte d'une marge de sécurité peut être considérée comme NDF > $35 \%$ MS.

\section{2 / Contrôle par la fibre physique}

Cet aspect avait été abordé par Sauvant (2000) sous l'angle des effets de la granulométrie du régime. Pour la base fibre physique, il est apparu également des interactions significatives avec les expériences (figure 4) :

$$
\begin{aligned}
& \mathrm{pH}=\mathbf{5 , 6 7}+\mathbf{0 , 2 4} \mathrm{TPa}+\mathbf{0 , 2 5 2} \mathrm{E} * \mathbf{T P a} \\
& \left(n=51, \mathrm{R}^{2}=0,98, \text { etr }=0,07\right)
\end{aligned}
$$

Ainsi, la pente ajustée de la réponse du $\mathrm{pH}$ aux variations de TPa est bien plus marquée lorsque celle-ci est déjà faible. Par exemple :

$$
\begin{aligned}
& \mathrm{dpH} / \mathrm{dTPa}=0,21 \text { quand } \mathrm{pH}=6,5 \\
& \mathrm{dpH} / \mathrm{dTPa}=1,14 \text { quand } \mathrm{pH}=5,8
\end{aligned}
$$

Figure 3. Influence de la teneur en NDF du régime sur le $\mathrm{pH}$ du rumen (synthèse bibliographique de D. Sauvant et D. Mertens 2001).

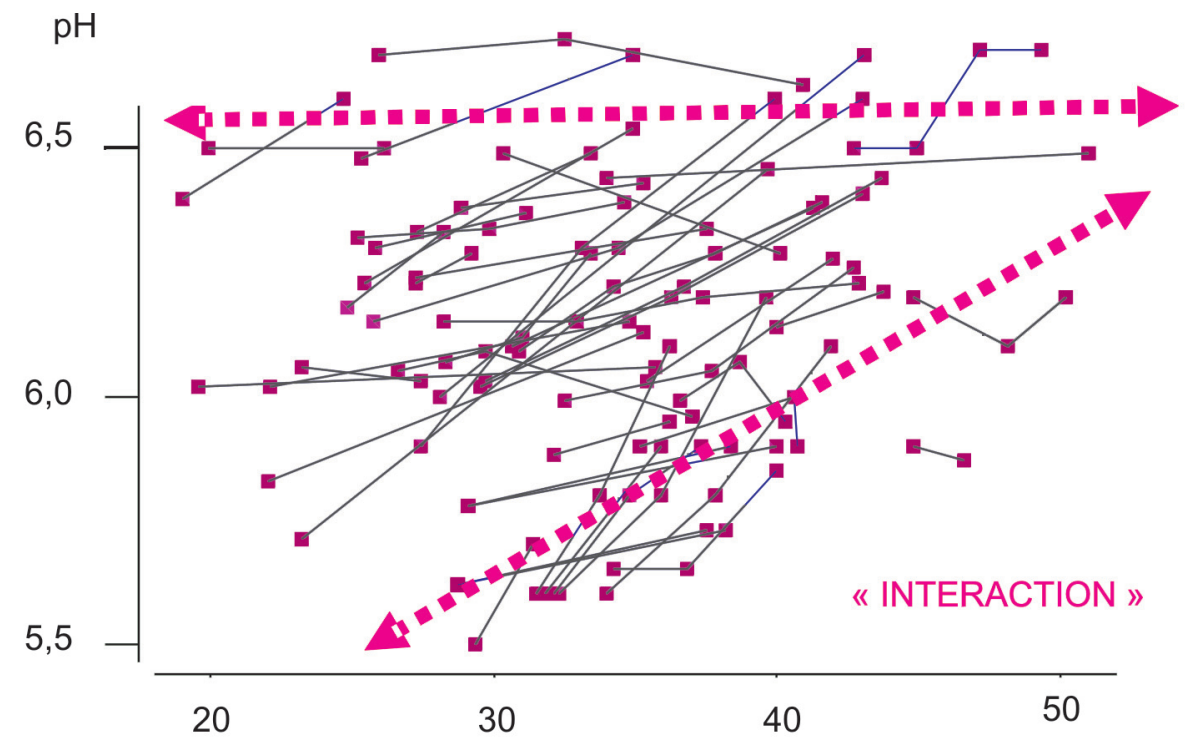


Figure 4. Influence de la taille des particules du régime sur le $\mathrm{pH}$ du rumen (synthèse bibliographique de D. Sauvant et D. Mertens 2001).

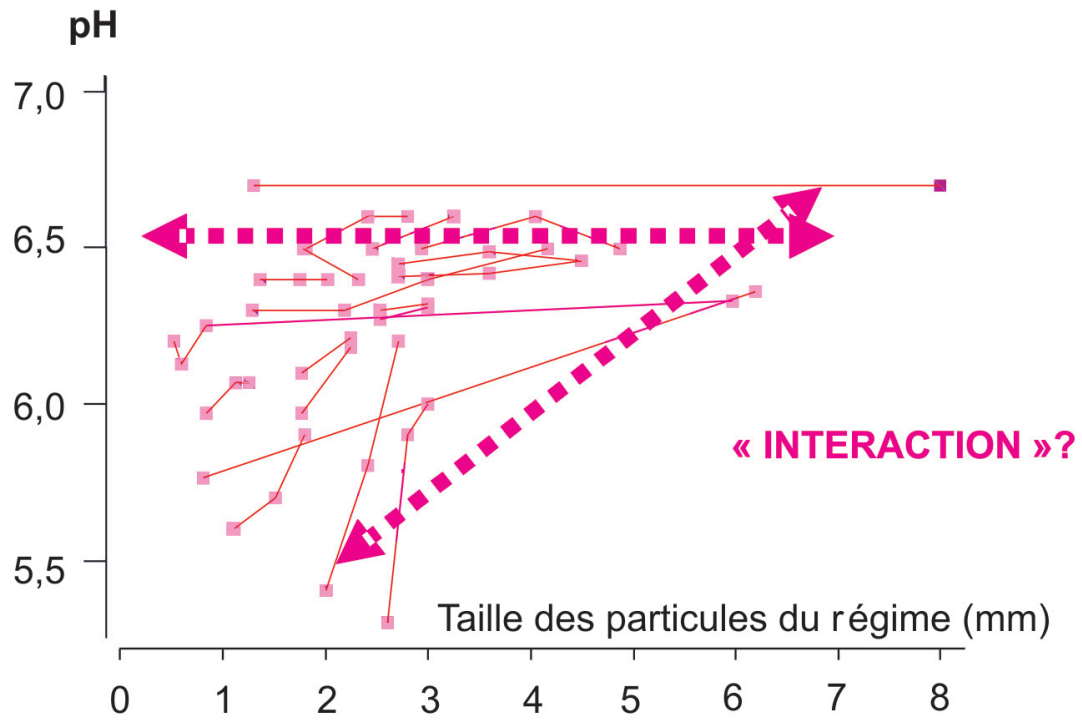

Ces résultats indiquent que la teneur minimale en fibres physiques qu'il convient de respecter pour maintenir un $\mathrm{pH}$ correct, est de l'ordre de $\mathrm{TPa}>$ $4 \mathrm{~mm}$.

Ces deux séries de résultats confirment, une fois encore, que la sensibilité du $\mathrm{pH}$ du rumen à la fibrosité du régime est d'autant plus marquée que le contenu de cet organe se trouve en état de sub-acidose. Ce résultat souligne l'importance de baser une prévention sur plusieurs critères à la fois.

\section{3 / Le débat actuel sur des critères de fibre physique}

Un débat demeure sur le choix du meilleur critère pour évaluer la fibre physique d'un régime. Dans la bibliographie, deux paramètres ont principalement été proposés : la taille moyenne des particules du régime $(\mathrm{TPa})$ et la proportion de matière sèche retenue par un tamis d'ouverture de $2 \mathrm{~mm}$ (P2). Pour comparer ces deux paramètres, nous avons rassemblé une base contenant 20 publications, 42 expériences et 99 traitements (Sauvant et Mertens 2002). Tous les traitements étaient caractérisés par des critères de $\mathrm{TPa}$ $(\mathrm{TPa}=3,1 \pm 1,2 \mathrm{~mm}, \min =0,8, \max =$ $8,0)$ et de $\mathrm{P} 2(\mathrm{P} 2=40,7 \pm 16,3 \%$, min $=4,4, \max =85,0)$. Dans cette base, ces deux paramètres ont été positivement, mais pas très précisément reliés :

$$
\begin{aligned}
& \mathbf{P 2}=\mathbf{7 , 4 4} \mathbf{T P a}+18.2 \\
& \left(n=99, \mathrm{R}^{2}=30,5 \% \text {, etr }=13,7 \%\right)
\end{aligned}
$$

$\mathrm{TPa}$ et $\mathrm{P} 2$ ont été comparés à travers leur relation avec différentes caractéris- tiques reconnues comme étant des indicateurs de la fibrosité du régime. Il s'agissait de la durée de mastication/jour $(\mathrm{MAST}=661 \pm 152 \mathrm{~min} / \mathrm{j}, n=93$, nexp $=39)$ ou par $\mathrm{kg}$ MSI (IM $=34,3 \pm$ $18,6 \mathrm{~min} / \mathrm{kg} \mathrm{MSI}, n=93$, nexp $=39)$, le $\mathrm{pH}$ du rumen $(\mathrm{pH}=6,14 \pm 0,31, n=42$, nexp $=18)$, le rapport $\mathrm{A} / \mathrm{P}$ du jus de rumen $(\mathrm{A} / \mathrm{P}=2,70 \pm 0,60, n=67, n \exp$ $=27)$, le $\mathrm{TB}$ du lait $(\mathrm{TB}=34,9 \pm$ $6,5 \mathrm{~g} / \mathrm{kg}, n=94$, nexp $=40$ ). Les résultats ont été traités par méta-analyse pour séparer les variations inter et intraexpérience.

Mis à part pour $\mathrm{P} 2$ comme prédicteur $\mathrm{du}$ rapport $\mathrm{A} / \mathrm{P}$, tous les modèles ont présenté des influences curvilinéaires de TPa et de P2. Les valeurs de $\mathrm{R}^{2}$ et d'écart type résiduel de l'ajustement des données ont été respectivement pour TPa et P2 de :

- 89 vs $90 \%$ et 68,1 vs $64,1 \mathrm{~min} / \mathrm{j}$ pour la durée de mastication

- 98 vs $98 \%$ et 3,1 vs 3,0 pour l'indice de mastication

-86 vs $91 \%$ et 0,16 vs 0,13 pour le $\mathrm{pH}$

- 84 vs $85 \%$ et 0,32 vs 0,30 pour le rapport $\mathrm{A} / \mathrm{P}$

- 93 vs $91 \%$ et 2,2 vs $2,1 \mathrm{~g} / \mathrm{kg}$ pour le TB du lait.

Ainsi les différences de précision ont été faibles entre les deux prédicteurs tout en étant systématiquement à l'avantage de $\mathrm{P} 2$ par rapport à $\mathrm{TPa}$. Pour la prédiction du $\mathrm{pH}$, les deux équations intra-expériences ont été :

$$
\mathrm{pH}=6,16-0,29 \mathrm{P2}+0,0006 \mathrm{P2}^{2}
$$$$
\left(n=46, \mathrm{R}^{2}=91 \%, \text { etr }=0,13\right)
$$

et

$\mathbf{p H}=\mathbf{5 , 1 4}+\mathbf{0 , 5 7} \mathbf{T P a}-0,068 \mathbf{T P a}^{2}$ $\left(n=46, \mathrm{R}^{2}=86 \%\right.$, etr $\left.=0,16\right)$.

Quand les résultats sont d'abord ajustés par les teneurs en NDF des régimes, les hiérarchies entre les critères $\mathrm{P} 2$ et $\mathrm{TPa}$ restent identiques. En conclusion de cette partie du travail, il apparaît que le minimum de fibrosité physique qu'il conviendrait de respecter serait de l'ordre de $\mathrm{TP}>4 \mathrm{~mm}$ et de $\mathrm{P} 2>40 \% \mathrm{MS}$.

On peut considérer que ces critères sont additifs, ils peuvent donc être pris en compte dans la formulation des régimes.

\section{4 / Recherche de critères synthétiques}

Différentes propositions ont été effectuées, en particulier par des chercheurs américains pour utiliser des critères synthétiques de prédiction du $\mathrm{pH}$ ruminal. Ces approches associent les deux types de fibre évoqués précédemment. Le concept le plus connu est celui de la «fibre effective» prôné par Mertens (1997). La fibre effective correspond à la teneur en NDF des particules $>1,18 \mathrm{~mm}$. En Europe, les Tables danoises et plus récemment les Tables hollandaises, ont proposé d'intégrer des critères de fibrosité et de structure pour calculer les rations. Ces critères combinent, d'une façon pas toujours explicite, des teneurs en fibres chimiques (évaluées par la teneur en cellulose brute, critère de moins en moins utilisé) et des indices de mastication sur la base des travaux de De Brabander et al (1996).

Un critère synthétique simple, et encore peu considéré, nous apparaît être la teneur en NDF de fourrage du régime offert (NDFF, \% MS). En effet, ce critère permet de prédire avec une bonne précision les différents paramètres révélateurs de l'état d'acidose. Sur la base des résultats de la première base de données citée dans ce texte, on peut en déduire que le minimum à respecter est NDFF > $20 \% \mathrm{MS}$.

\section{4 / Equilibre entre la pro- duction d'acide et le recy- clage des tampons en condi- tions pratiques}

Une question importante, relative à l'acidose, est de savoir lequel de la production d'acide dans le rumen et du recyclage des tampons par la salive et la mastication joue le rôle le plus 
important vis-à-vis de l'occurrence de l'acidose ruminale.

\section{1 / Estimation de la production des acides}

Les AGV produits le sont à proportion étroite de la quantité de matière organique fermentée dans le rumen. Celle-ci peut être prédite à partir des teneurs en matière organique digestible (MOD) et en protéines (PIA) et amidon (AMND) non dégradé dans le rumen ainsi que la teneur en extrait éthéré (EE) :

$$
\begin{gathered}
\text { AGV }=0,75 * 0,70 * \\
(\text { MOD - PIA - AMND - EE) }
\end{gathered}
$$

Pour estimer la production d'AGV, on suppose que $30 \%$ de la MOF est transformée en MO microbienne et que $75 \%$ du flux de carbone sous forme d'AGV et de gaz est sous forme d'AGV. Pour les 14 matières premières considérées dans l'étude in vitro du pouvoir acidogène (figure 1), le $\mathrm{pH}$ ruminal obtenu est très lié aux quantités d'AGV produites ainsi estimées :

$$
\begin{aligned}
& \text { pH = 6,33 - 0,013 AGV\%MS } \\
& (n=14, \text { etr }=0,09) \text {. }
\end{aligned}
$$

\section{2 / Estimation du recyclage des tampons}

La sécrétion salivaire est connue depuis longtemps comme étant la principale voie de recyclage des tampons endogènes chez le ruminant. Cependant, la mesure de ce flux est très difficile et n'a que très rarement été faite. Une publication intéressante de Jacques et al (1989) a suggéré que les flux, ou sécrétions, salivaires et de liquide au duodenum (FLD) étaient étroitement liées. En conséquence, le FLD peut être considéré comme une estimation par excès du flux salivaire. Etant donné que le FLD a été fréquemment mesuré, Sauvant et al (1999) ont étudié sa relation avec les activités masticatoires et les critères de fibrosité. La consommation quotidienne d'eau alimentaire est de l'ordre de $4 \mathrm{~L} / \mathrm{kg}$ MSI tandis que le FLD varie entre 5 et plus de $20 \mathrm{~L} / \mathrm{kg}$ MSI.

Quand le FLD et l'indice de mastication sont étudiés simultanément et que les résultats des différentes publications les indiquant sont synthétisés, il apparaît une relation assez précise entre ces deux paramètres. La pente de la régression obtenue indique une sécrétion d'environ $300 \mathrm{~mL}$ de salive/mn de mastication ; ce résultat est cohérent avec différentes estimations de la sécrétion salivaire disponible dans la littérature. Pour évaluer le recyclage des tampons, il a été supposé que la teneur en tampons de la salive était égale à $120 \mathrm{mEq} / \mathrm{L}$ pour les bicarbonates et à $25 \mathrm{mEq} / \mathrm{L}$ pour les phosphates, ceci équivaut à $11.35 \mathrm{~g} / \mathrm{L}$ en terme de bicarbonate (Sauvant et al 1999). Avec ces hypothèses, $1 \mathrm{mn}$ de mastication procure à peu près $3,4 \mathrm{~g}$ de bicarbonate. En outre, le minimum généralement admis pour l'index de mastication $(40 \mathrm{mn} / \mathrm{kg}$ MSI) correspond à environ $12 \mathrm{~L}$ de salive, soit $136 \mathrm{~g}$ de bicarbonate $/ \mathrm{kg}$ MSI. Cette valeur est bien plus importante que les recommandations d'apport supplémentaire de bicarbonate au régime (voir plus haut).

Il a été montré que le FLD était largement expliqué par les paramètres de la fibrosité :

$$
\begin{gathered}
+1 \% \text { NDF/DM }>>+\mathbf{0 , 1 7} \\
\pm 0.02 \mathrm{~L} \text { de FLD/MS } \\
(n=160, \text { nexp }=66) \\
\text { et } \\
+\mathbf{1} \mathbf{m m ~ M P S ~} \gg>+\mathbf{0 , 3 8} \\
\pm \mathbf{0 . 0 2} \mathbf{L} \text { de FLD/MS } \\
(n=27, n \exp =10)
\end{gathered}
$$

Figure 5. Influence de la teneur en matière organique digestible in vivo sur le $\mathrm{pH} d u$ rumen (synthèse bibliographique de D. Sauvant et D. Mertens 2004).

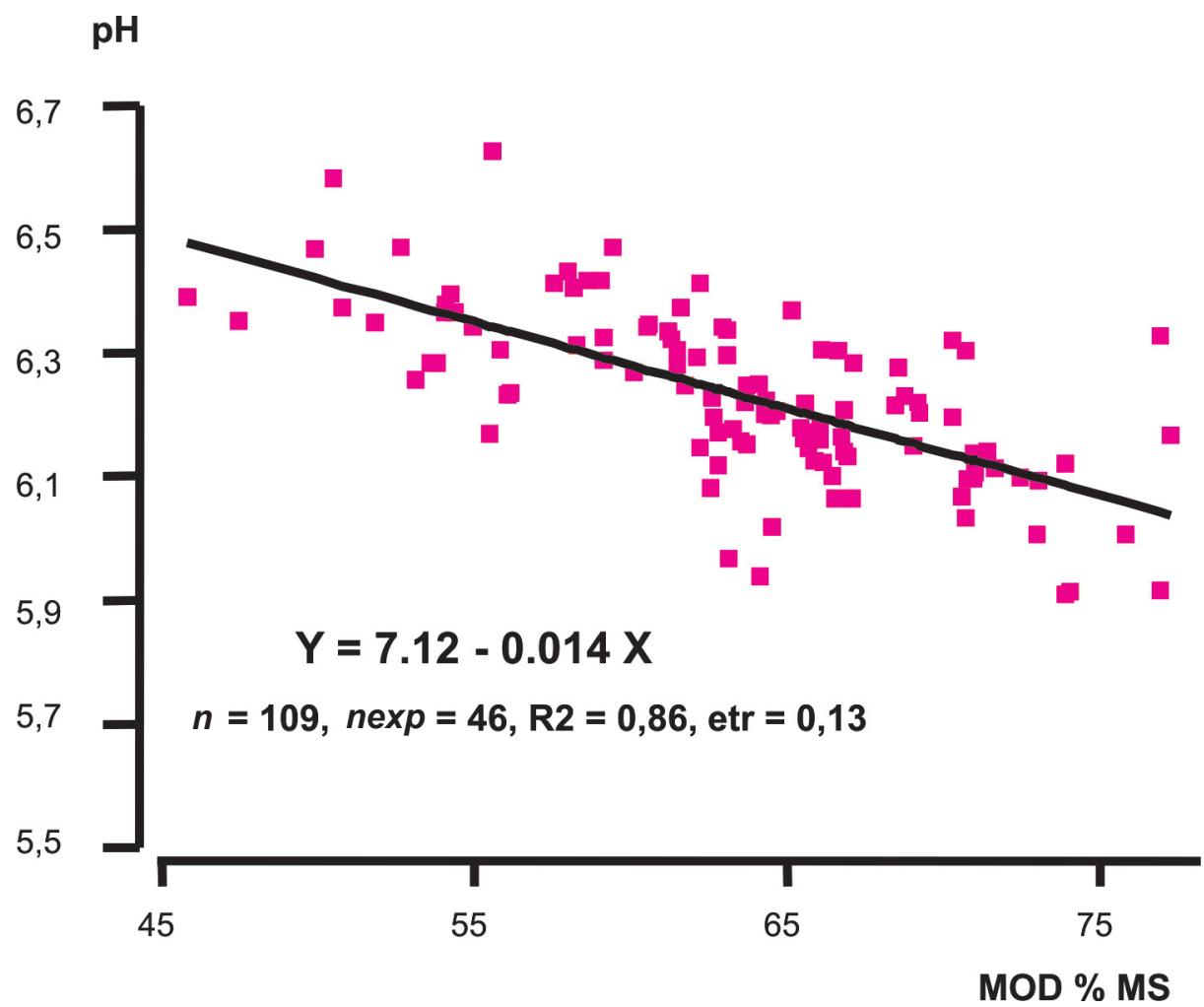




$$
\begin{gathered}
\mathbf{p H}=\mathbf{7 , 1 2}-\mathbf{0 , 0 1 4} \text { MOD\%MS } \\
(n=109, \text { nexp }=46, \text { etr }=0,13)
\end{gathered}
$$

D'après cette équation, le $\mathrm{pH}$ devient inférieur à 6 lorsque MOD $>70 \%$ de MS.

Le $\mathrm{pH}$ du rumen a été prédit plus précisément à partir du FLD (figure 6) :

$$
\begin{aligned}
& \text { pH }=4,96+0,15 \text { FLD }-0,003 \text { FLD }^{2} \\
& (n=86, n \exp =35, \text { etr }=0,09)
\end{aligned}
$$

La hiérarchie de précision entre les deux approches se confirme pour le rapport $\mathrm{A} / \mathrm{P}$ des $\mathrm{AGV}$ du rumen. L'influence du FLD sur le $\mathrm{pH}$ peut être dû non seulement au recyclage des tampons, mais également au flux accru d'AGV vers l'intestin :

$$
\begin{aligned}
& \mathrm{A} / \mathrm{P}=\mathbf{- 0 , 5 9}+\mathbf{0 , 5 0} \mathrm{MOD}-\mathbf{0 , 0 1 1} \mathrm{MOD}^{\mathbf{2}} \\
& (n=79, \text { nexp }=32, \text { etr }=0,46) \\
& \mathrm{A} / \mathrm{P}=\mathbf{- 0 , 5 7}+0,52 \mathrm{FLD}-0,014 \mathrm{FLD}^{2} \\
& (n=75, n \exp =30, \text { etr }=0,30)
\end{aligned}
$$

D'après cette équation et la figure 6, le $\mathrm{pH}$ devient inférieur 6 lorsque FLD est inférieur à 9-10 L/kg MS.

Lorsque l'on considère le rapport acétate/propionate, FLD est également un meilleur prédicteur que la MOD. En conclusion partielle, il apparait que le FLD, qui est étroitement dépendant du critère de fibrosité, est plus lié aux perturbations des fermentations ruminales que les quantités de MO fermentées dans le rumen, donc sans doute d'AGV produit. Cela veut dire qu'en pratique, il importe de se préoccuper plus des critères de mastication et de fibrosité de régime que de concentration en énergie du régime.

\section{5 / Aspects animaux et microbiens influençant le pH du rumen}

\section{1 / Les influences du niveau d'ingestion, de la capacité du rumen et du temps de séjour des digesta dans cet organe}

Pour estimer l'influence du niveau d'ingestion, nous avons rassemblé une base de 35 expériences et 75 traitements regroupant des expériences dans lesquelles le seul facteur expérimental était le niveau en matière sèche ingérée. Il apparaît une relation intra expérience négative entre le $\mathrm{pH}$ du rumen et le niveau d'ingestion :

Figure 6. Influence entre le flux de liquide au duodenum et le $\mathrm{pH}$ du rumen (synthèse bibliographique de D. Sauvant et D. Mertens 2004).

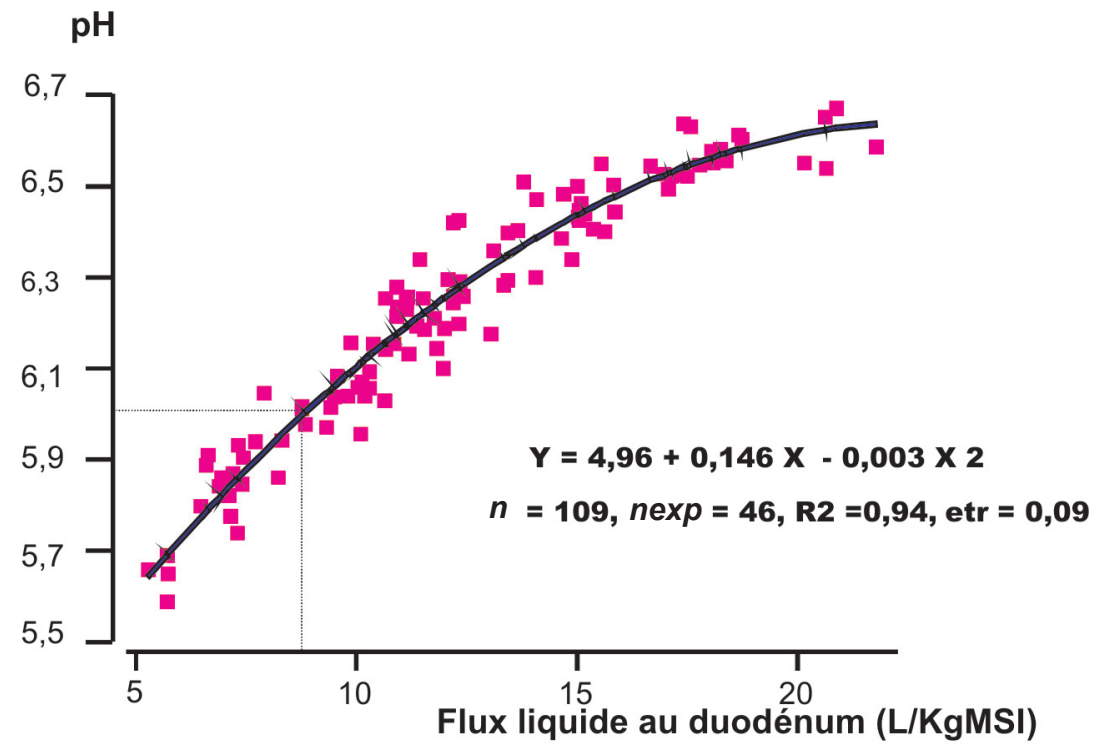

$$
\begin{array}{r}
\mathbf{p H}=\mathbf{6 , 8}-\mathbf{0 , 2 1} \mathbf{M S I} \% \mathbf{P V} \\
(n=75, n \exp =35, \text { etr }=0,12)
\end{array}
$$

Cette régression indique que le $\mathrm{pH}$ passe sous le seuil de 6,0 lorsque MSI $>3,8 \% \mathrm{PV}$. Cette relation est la conséquence du fait que, lorsque la MSI augmente, l'accroissement de la MOF, donc la production d'AGV, est en relatif plus marqué que celui du volume du rumen. Ceci contribue à expliquer pourquoi des animaux à haut niveau de production sont plus sensibles à l'acidose.

En partie en liaison avec les aspects évoqués ci-dessus, la capacité du rumen et la durée de transit ont une influence marquée sur le $\mathrm{pH}$ ruminal. Pour étudier cet aspect, nous avons sélectionné des expérimentations dans lesquelles le facteur était la teneur en concentré ou en NDF du régime. Pour une partie de ces travaux, le volume ou le poids des liquides ruminaux ont été mesurés. Ceci a permis d'en déduire la capacité du rumen rapportée à la MSI. Ce critère exprimé en $\mathrm{kg}$ de liquide de rumen/kg MSI est proportionnel à la durée de présence des aliments dans le rumen, ainsi qu'au FLD évoqué plus haut. Ce critère est également proportionnel à la surface d'absorption ruminale/kg MSI. Il apparaît que le $\mathrm{pH}$ du rumen est très influencé par ce critère d'encombrement. La relation n'est pas linéaire et il apparaît une chute marquée du $\mathrm{pH}$ quand l'encombrement devient inférieur au seuil de $5 \mathrm{~kg}$ de liquide/kg MSI (figure 7). Une telle situation à risque est observée chez des animaux à haut niveau de production recevant des régimes pauvres en fourrages, donc peu encombrants.

\section{2 / Les influences des popula- tions microbiennes du rumen}

La sensibilité des espèces microbiennes au $\mathrm{pH}$ varie largement. De nombreux travaux ont étudié ces aspects, cependant pour un substrat donné, on ne sait pas grand chose sur la capacité intrinsèque d'une population microbienne mixte à accélérer ou à décélérer l'évolution du $\mathrm{pH}$ in vivo. Un aspect partiellement relié au précédent a cependant été étudié. Il s'agit de la capacité de certains protozoaires, ou certaines bactéries, à stocker de façon transitoire de l'amidon ou «du glycogène spécifique» après un repas (Jouany et Thivend 1972). Ce phénomène n'est pas négligeable puisque le stockage cellulaire d'amidon peut atteindre $30 \%$ de la MS bactérienne (figure 8, Sauvant et Van Milgen 1995). Un tel phénomène peut être considéré comme un «délai digestif» de plusieurs heures permettant d'atténuer les effets de la vitesse de fermentation de l'amidon et d'amortir ainsi la chute du $\mathrm{pH}$ ruminal.

Un autre aspect connu concerne l'influence de la défaunation sur le $\mathrm{pH} d u$ rumen. A partir d'une base de 90 publications et 169 comparaisons, Eugène et al (2004), ont montré qu'il y avait une interaction significative entre les effets de la défaunation et de la proportion de concentré sur le $\mathrm{pH}$ du rumen. En effet, la réponse $\mathrm{du} \mathrm{pH}$ à la défaunation est positive lorsque la proportion de concentré est inférieure à environ $50 \%$ de la MSI et négative au dessus de ce seuil. La capacité de stockage de l'amidon par les protozoaires évoquée cidessus permet d'expliquer, en partie au moins, cette interaction. 
Figure 7. Influence de la capacité du rumen par $\mathrm{kg}$ MSI sur le $\mathrm{pH}$ moyen (synthèse bibliographique de $D$. Sauvant et $D$. Mertens non publié).

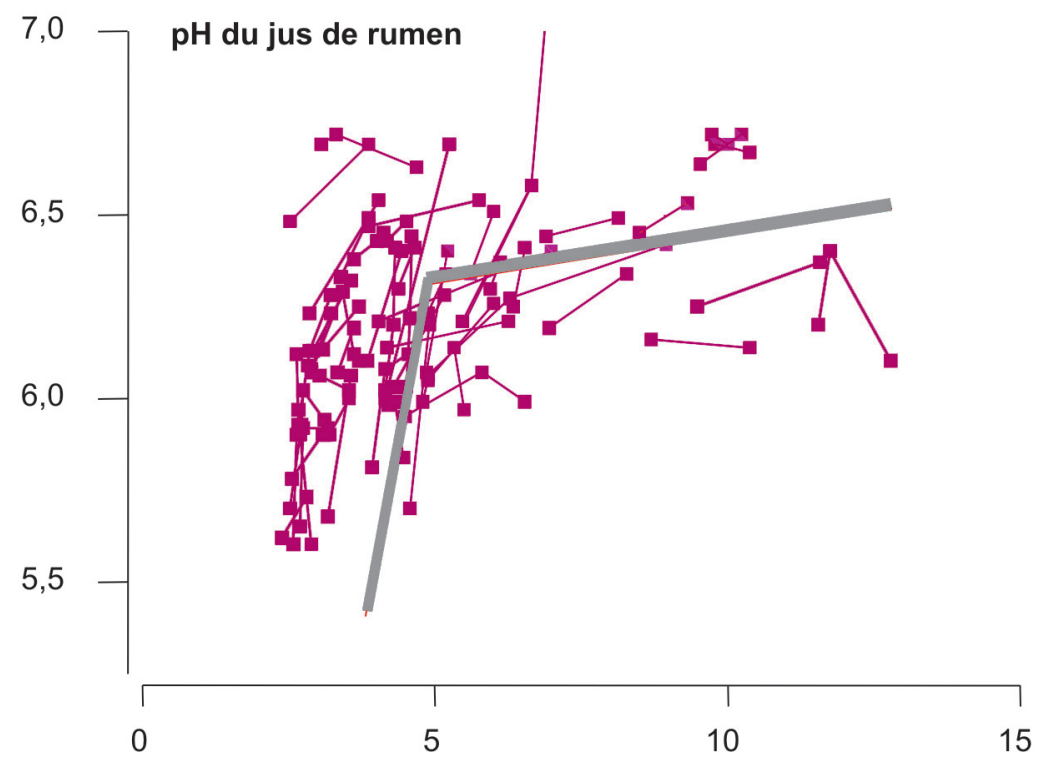

Capacité rumen (L/kg MSI)

Figure 8. Evolution de la teneur en glucides stockés dans les cellules microbiennes du rumen.

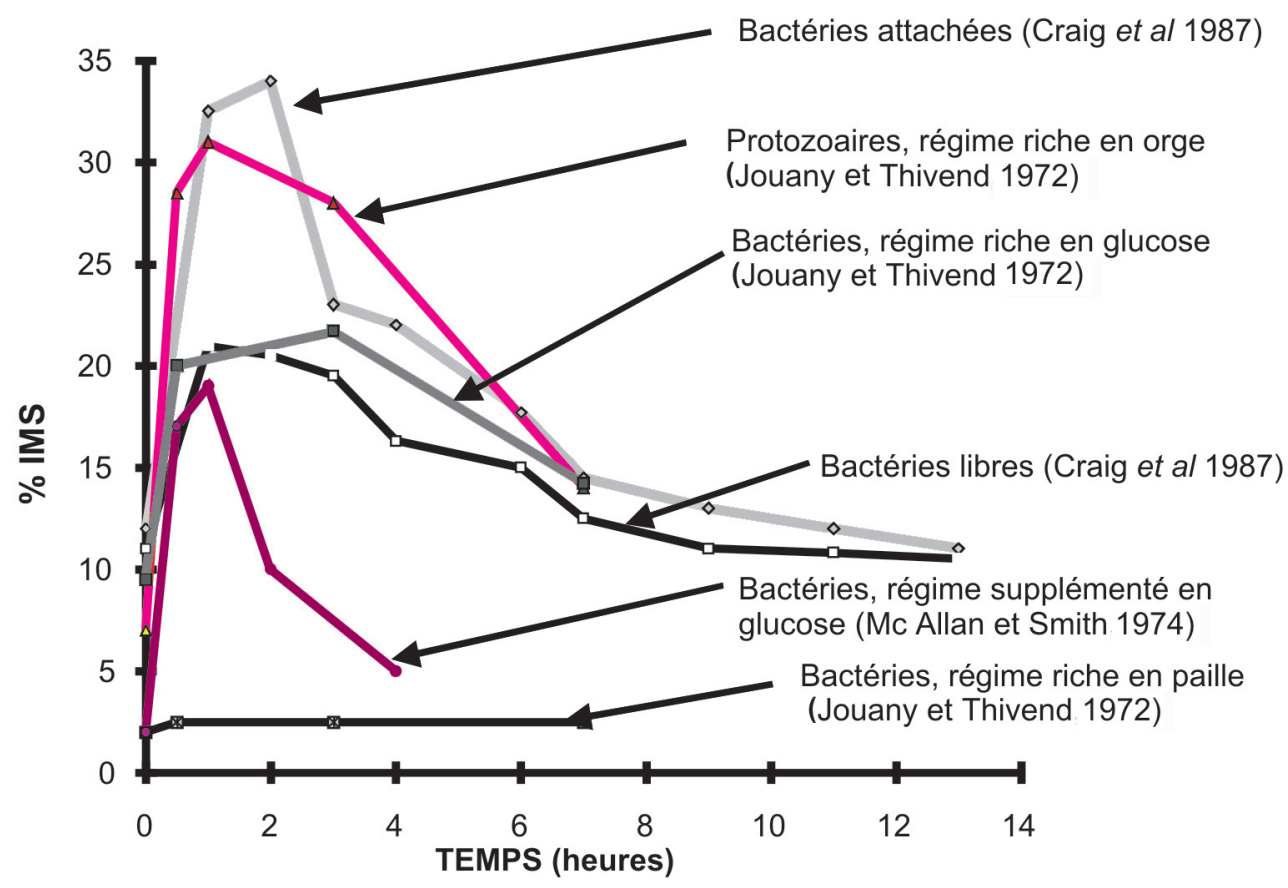

\section{Conclusions}

De nombreuses causes sont impliquées dans les variations du $\mathrm{pH}$ du rumen et plusieurs revues ont déjà été consacrées au déterminisme de l'acidose. L'objectif de ce travail de synthèse n'était pas d'être exhaustif sur un sujet aussi vaste ou de fournir une nouvelle revue «qualitative», d'autres aspects ont été abordés dans les deux publications sur l'acidose de ce dossier d'INRA Productions Animales (Martin et al 2006, Peyraud et Apper-Bossard 2006). L'attention a été focalisée sur les facteurs pour lesquels des relations quantitatives et significatives, donc utilisables en formulation des régimes, peuvent être extraites des données de la littérature.

Il apparaît qu'il y a plusieurs moyens pour formuler des régimes en intégrant des paramètres permettant de contrôler le $\mathrm{pH}$ ruminal. Aucun des paramètres évoqués ne s'avérant nettement plus précis que les autres, il nous semble important de chercher à combiner plusieurs de ces indicateurs lors de la formulation des régimes. Un aspect important est ressorti plusieurs fois dans cette étude, il concerne les interactions marquées entre les effets des facteurs et les valeurs initiales du $\mathrm{pH}$, soulignant ainsi qu'un état de sub-acidose est la première cause d'une grande sensibilité aux facteurs acidogéniques. Sauvant et al (1999), ont publié un modèle empirique pour prédire le $\mathrm{pH}$ du rumen et l'état d'acidose. Depuis 1999, de nombreux résultats ont été publiés et la majeure partie d'entre eux ont été inclus dans la présente approche. Celle-ci permet donc de disposer d'un jeu actualisé d'indicateurs pour prévenir l'état d'acidose du rumen. 


\section{Références}

Apper-Bossard E., Peyraud J.L., Faverdin P., Meschy F., 2004. Effets du bilan alimentaire cations-anions sur les performances zootechniques des vaches laitières selon les teneurs en énergie rapidement dégradable et en protéines des rations. Renc. Rech. Rum., 11, 251-254

Brossard L., 2004. Compréhension de l'évolution de l'acidose ruminale latente et prévention par addition de levures vivantes (Saccharomyces cerevisiae I-1077, Levucell ${ }^{\circledR}$, SC), Thèse ENSAR, 161p.

Brossard, L., F. Chaucheyras-Durand, F., Michalet-Doreau, B., Martin, C. 2006. Dose effect of live yeasts on rumen microbial communities and fermentations during butyric latent acidosis in sheep: new type of interaction. Anim. Sci., Sous presse.

Chaucheyras F., 1995. Effets de deux souches de Saccharomyces cerevisiae, utilisées comme additif alimentaire pour le ruminant, sur l'activité in vitro de quelques microorganismes du rumen. Thèse, Université Blaise Pascal, Clermont-Ferrand, 101p.

De Brabander D. L., De Boever J. L., De Smet A. M., Vanacker J. M., Boucqué C. V., 1996. Evaluation de la structure physique dans l'alimentation de la vache laitière. Version succincte. Structuurwaardering in de Melkveevoeding., Ministerie van Middenstand en Landbouw, Brussels Belgium, 16p

Dishington I. W., 1975. Prevention of milk fever (hypocalcemic paresis puerperalis) by dietary salt supplements. Acta Vet. Scand., 16, 503-512.

Dragomir, C., Michalet-Doreau, B., Peyraud, J.L. Sauvant, D..2003. Integrative parameters of $\mathrm{pH}$ kinetics as indicators of ruminal acidosis. VIth Int. Symp. Nutr. Herbivores, 19-24 October 2003, Merida, Yucatan, Mexico, 3, 225 227.

Dragomir C., Sauvant D., Michalet-Doreau B., Peyraud J.L., Giger-Reverdin S., 2005. Metaanalysis of $0-8$ hours post-prandial kinetics of ruminal $\mathrm{pH}$. Non publié.

Eugène M., Archimède H., Sauvant D., 2004. Quantitative meta-analysis on the effects of defaunation of the rumen on growth, intake and digestion in ruminants. Livest. Prod. Sci., 85, 81 97.

Giger-Reverdin S., Duvaux-Ponter C., Sauvant D., Martin O., Nunes do Prado I., Muller R., 2002. Intrinsic buffering capacity of feedstuffs. Anim. Feed Sci. Technol., 96, 83-102.

Giger-Reverdin S., Martin O., Sauvant D., 2003. Modélisation du pouvoir tampon du contenu ruminal. Recherche de l'effet de la nature de la ration. Renc. Rech. Rum. 10, 173.

Giger-Reverdin S., Sauvant D., 2001. Metaanalysis of the acidogenicity of ingredients. J.
Dairy Sci., 84 (Suppl. 1), J. Anim. Sci., 79 (Suppl. 1), Poult. Sci., 80 (Suppl. 1): 79, (Abst 328).

Giger-Reverdin S., Sauvant D., Chapoutot P., 2000. Comparaison de deux méthodes d'étude de la dégradation à court et moyen termes des aliments pour les ruminants (in sacco et production de gaz in vitro). Renc. Rech. Rum., 7, 206.

Giger-Reverdin S., Sauvant D., Tessier J., Bertin G., Morand-Fehr P., 2004. Effect of yeast culture supplementation on rumen fermentation in lactating dairy goats. S. Afr. J. Anim. Sci., 34 (Suppl. 1), 59-61.

Jacques K., Harmon D. L., Croom W. J., Jr., Hagler W. M., Jr., 1989. Estimating salivary flow and ruminal water balance of intake, diet, feeding pattern, and slaframine. J. Dairy Sci., 72, $443-452$

Jouany J. P. Thivend P., 1972. Evolution posprandiale de la composition glucidique des corps microbiens du rumen en fonction de la nature des glucides du regime. I. Les protozoaires. Ann. Biol. Anim. Biochim. Biophys., 12, 673-677.

Martin C., Brossard L., Doreau M., 2006. Mécanismes d'apparition de l'acidose ruminale latente et conséquences physiopathologiques et zootechniques. INRA Prod. Anim., 19 (2), 93108

Mertens D. R., 1997. Creating a system for meeting the fiber requirements of dairy cows. J. Dairy Sci., 80, 1463-1481.

Meschy F., Bravo D., Sauvant D, 2004 Métaanalyse des réponses de la vache laitière à la supplémentation en substances tampons. INRA Prod. Anim., 17, 11-18.

Meschy F., Peyraud J.L., 2004. Teneurs en ions forts des fourrages et calcul de la valeur de leur bilan alimentaire cations-anions et de leur bilan électrolytique. Renc. Rech. Rum., 11, 255258.

Nisbet D. J., Martin S. A., 1991. Effect of a Saccharomyces cerevisiae culture on lactate utilization by the ruminal bacterium Selenomonas ruminantium. J. Anim. Sci., 69, 4628-4633.

Offner A., Bach A., Sauvant D., 2003. Quantitative review of in situ starch degradation in the rumen. Anim. Feed Sci. Technol., 106, 8193.

Owens F. N., Secrist D. S., Hill W. J., Gill D. R., 1998. Acidosis in cattle: a review. J. Anim. Sci., 76, 275-286.

Peyraud J.L., Apper-Bossard E., 2006. L'acidose latente chez la vache laitière. INRA Prod. Anim., 19 (2), 79-92.

Rossi F., Cocconcelli P.S., Masoero F., 1995, Effect of a Saccharomyces cerevisiae culture on growth and lactate utilisation by the ruminal bacterium Megasphaera elsdenii. Ann.Zootech., 44, Suppl., 403-409.

Sauvant, D., 2000. Granulométrie des rations et nutrition du ruminant. INRA Prod. Anim., 13 (2), 99-108

Sauvant D., Giger-Reverdin S., Schmidely P., 2004. Rumen acidosis: modeling ruminant response to yeast culture. In: Lyons T.P., Jacques K.A. (Ed.) Re-imagining the feed industry. Nutritional biotechnology in the feed and food industries. Proceedings of Alltech's 20th Annual Symposium, Nottingham University Press, UK, 221-229.

Sauvant D., Martin C., Peyraud J.L., 2006 Introduction générale. In : Dossier, L'acidose chez les ruminants. INRA Productions Animales, 19 (2), 69-78.

Sauvant D., Mertens D. R., 2001. Empirical modeling of ruminal $\mathrm{pH}$ from dietary NDF and mean particle size. J. Dairy Sci., 84 (Suppl. 1), J. Anim. Sci., 79 (Suppl. 1), Poult. Sci., 80 (Suppl. 1), 198-199 (Abst. 824).

Sauvant D., Mertens D. R., 2002. Is fibrosity better evaluated by dietary mean particle size or percentage of dry matter retained by a $2 \mathrm{~mm}$ sieve ? J. Dairy Sci., 85 (Suppl. 1), J. Anim. Sci., 80 (Suppl. 1), 106 (Abst. 421).

Sauvant D., Mertens D. R., 2004. Is ruminal acidosis related to high diet fermentability or low buffer recycling ? J. Dairy Sci., 81, (Suppl. 1), 271.

Sauvant D., Meschy F., Mertens D., 1999. Les composantes de l'acidose ruminale et les effets acidogènes des rations. INRA Prod. Anim., 12, 49-60.

Sauvant D., Perez J. M., Tran G., 2004. Tables de composition et de valeur nutritive des matières premières destinées aux animaux d'élevage. Porcs, volailles, bovins, ovins, caprins, lapins, chevaux, poissons. INRA Editions, Paris, France, 301p.

Sauvant D., Schmidely P., Daudin J.J., 2005. Les méta-analyses des données expérimentales application en nutrition animale. INRA Prod. Anim., 18 (1), 63-75.

Sauvant D., Van Milgen J., 1995. Dynamic aspects of carbohydrate and protein breakdown and the associated microbial matter synthesis. In: Engelhardt W.V., Leonhard-Marek S., Breves G., Giesecke D. (Ed.) Ruminant physiology: digestion, metabolism, growth and reproduction. Proceedings 8th International Symposium on Ruminant Physiology, Delmar Publishers, Albany Germany, 71-91.

Sauveur B, Mongin P. 1978. Tibial dyschondroplasia, a cartilage abnormality in poultry Ann. Biol. Anim. Biochim. Biophys., 18, 87-98.

\section{Résumé}

Le principal critère d'évaluation de l'acidose du rumen est le $\mathrm{pH}$ moyen mesuré pendant plusieurs heures après le repas. D'autres critères ont été proposés, cependant ils restent très corrélés au précédent et ne fournissent pas d'information plus pertinente.

Différentes mesures peuvent être effectuées sur les aliments, ou les régimes alimentaires, pour évaluer le risque d'acidose ruminale. Au niveau des aliments, il est ainsi possible de mesurer leur pouvoir tampon propre, leur fermentescibilité in vitro, ou la chute de pH induite, et la dégradabilité à court terme $(4 \mathrm{~h})$ in sacco de leur MS. D'autres critères peuvent être utilisés, il s'agit en particulier de la teneur en amidon dégradable pour les matières premières amylacées. Enfin, le bilan cation-anion peut aussi être évalué au niveau des aliments et être utilisé pour évaluer une facette du pouvoir acidogène des aliments. Au niveau des régimes, la fibrosité représente un facteur essentiel 
de risque d'acidose ; il y a en fait deux composantes de fibrosité, la fibrosité chimique, quantifiée par la teneur en NDF (NDF/MS $>35 \%$ ), la fibrosité physique évaluée par la taille moyenne des particules (TP $>4 \mathrm{~mm})$, ou la proportion de MS retenue à un tamis de $2 \mathrm{~mm}(\mathrm{P2}>$ $40 \%$ ). Il est possible de chercher à combiner ces deux types de critères. Les critères de fibrosité sont très importants dans la mesure où ils déterminent l'activité masticatoire et, de ce fait, le recyclage des tampons ainsi que le flux liquidien ruminal, critères plus déterminants de l'acidose que ceux qui prédisent la production des AGV. D'autres aspects interviennent de façon non négligeable dans le risque d'acidose, il s'agit en particulier du niveau d'ingestion ainsi que du rôle de certaines populations microbiennes du rumen telles que les protozoaires. Outre les facteurs relatifs aux aliments et aux rations, il est possible d'envisager des supplémentations de substances préventives, c'est en particulier le cas des substances tampons et de certaines substances probiotiques.

L'ensemble des équations et recommandations proposées permettent de tenir compte de différents critères pour prévenir le risque d'acidose latente.

\section{Abstract}

\section{The control of latent ruminal acidosis}

The major item to assess ruminal acidosis is the mean $\mathrm{pH}$ of rumen juice for several hours after a meal. Other criteria have been proposed, however they are closely related to the mean $\mathrm{pH}$ and do not provide more relevant information.

Various types of measurements can be performed on feeds, or diets, to evaluate the risk of latent acidosis. Individual feeds can be assessed in terms of buffering capacity, in vitro fermentability or $\mathrm{pH}$ drop capacity, and in sacco short term (4h) DM diseappearance. Other parameters can be measured, such as in particular the degradable starch for starchy ingredients. Otherwise, the cation-anion balance can be calculated to assess one of the components of feed and diet acidogenicity. Diet fibrosity is a major factor of variation of the risk of acidosis. In fact, there are two components of fibrosity : the chemical fibrosity, assessed by the dietary NDF (NDF\%DM>35\%), and the physical one, assessed by either the mean particle size (MPS $>4 \mathrm{~mm}$ ) or the dietary DM retained by a $2 \mathrm{~mm}$ aperture sieve (P2 $>40 \% \mathrm{DM})$. It is also possible to combine these two types of parameters. Fibrosity items are very important because they determine the chewing activities and thus the salivary buffer recycling and the liquid flow throughout the rumen. These items seem to be more influent than those predicting the VFA production. Other aspects affect ruminal acidosis such as the level of intake and the role of some microbial sub populations in the rumen such as the protozoa. Otherwise, beyond the feeding factors, diets can be corrected to prevent acidosis by supplementation of buffer substances or probiotics.

The proposed equations and recommendantions allow tointegrate various items to formulate diets preventing the risk of latent acidosis.

SAUVANT D., GIGER-REVERDIN S., MESCHY F., 2006. Le contrôle de l'acidose ruminale latente. INRA Prod. Anim., 19, 69-78. 